\title{
PLANIALTIMETRIC ACCURACY EVALUATION OF DIGITAL SURFACE MODEL (DSM) AND DIGITAL TERRAIN MODEL (DTM) OBTAINED FROM AERIAL SURVEY WITH LIDAR
}

\author{
C. B. M. Cruz ${ }^{\text {a }}$, R. S. Barros ${ }^{\text {a }}$, L. M. L. Rabaco ${ }^{\text {b }}$ \\ ${ }^{\text {a }}$ Departamento de Geografia, Instituto de Geociências, Universidade Federal do Rio de Janeiro, A. Athos da Silveira \\ Ramos, 274 - bloco I, Rio de Janeiro, Brazil (cmad, rafael.barros)@ufrj.br \\ ${ }^{\mathrm{b}}$ Centro de Pesquisas e Desenvolvimento (CENPES)/Petrobras, Av. Horácio de Macedo, 950 \\ CEP 21941-915 - Ilha do Fundão - Rio de Janeiro - Brazil \\ lismaria@petrobras.com.br
}

Commission I/2

KEY WORDS: LIDAR, planialtimetric accuracy, DTM, DEM

\begin{abstract}
:
It's noticed a significant increase in the development of orbital and airborne sensors that enable the extraction of three-dimensional data. Consequently, it's important the increment of studies about the quality of altimetric values derived from these sensors to verify if the improvements implemented in the acquisition of data may influence the results. In this context, as part of a larger project that aims to evaluate the accuracy of various sensors, this work aims to analysis the planialtimetric accuracy of DSM and DTM generated from an aerial survey with LIDAR, using as reference for the planimetric analysis of the orthophotos obtained. The project was developed for an area of São Sebastião city, located in the basin of the North Coast of São Paulo state. The area's relief is very steep, with a predominance of dense forest vegetation, typical of the Atlantic Forest. All points have been established in the field, with the use of GNSS of one frequency (L1) through static relative positioning, acquiring a minimum of 1,500 epochs, for a distance less than $20 \mathrm{~km}$ to the base. In this work it's considered the Brazilian standard specifications for classification of cartographic bases (PEC). The Brazilian company responsible for the aerial survey (LACTEC) gave the following products for analysis: point clouds in raw format ( $\mathrm{x}, \mathrm{y}, \mathrm{z})$ using orthometric heights; point clouds (first and last pulse) for each range of flight to verify systematic errors; DTM uniformly spaced, filtering small natural obstacles, buildings and vegetation, in Geotiff format; DSM also uniformly spaced, in Geotiff format; and the mosaic of georeferenced digital images. The analysis realized on products from the LIDAR indicated their adoption to the scales 1:2,000 (Class A for the orthophotos and Class B for the DTM) and 1:5,000 (class C for the DSM). There were no indications of trends in the results. The average error was $0.01 \mathrm{~m}$. It's important that new areas with different topographic characteristics may be evaluated to get an indication for other situations. As to the assessment of the altimetric accuracy, we are going to do more analysis with points obtained under the forest canopy in order to be able to assess the real accuracy of the DTM in areas with forest cover. Studies that focus the development of new methodologies for obtaining Digital Elevation Models (DEM) are very important, especially in large scales, seeking to generate data with cost-benefit's advantages. This way, topographic features can be obtained for wider areas of our country, meeting the needs of most studies and activities related to the representation of these kind of data.
\end{abstract}

\section{INTRODUCTION}

The interest in research on altimetry obtained from the new remote sensing products has grown to meet the reference and thematic cartography. Fernandes (2004) and Gomes (2002) are examples of using altimetry in studies related to thematic areas, while Toutin et al. (2002), Toutin (2004), Gonçalves et al. (2005) and Barros (2006) exemplify applications related to reference cartography.

Moreover, it's observed a significant increase in developing sensors, from aerial or orbital surveys, that allow extracting three-dimensional data. Consequently, also increases the need to study the quality of altimetry obtained from these sensors, as well as the need for verification of the actual contribution of these technologies in the data acquisition process.

In the case of new methodologies for obtaining Digital Elevation Models (DEM) to meet expectations, reaching scales of more detail, will have taken an important step in order to generate data in a cost-benefit advantages, especially in the time question, when compared to conventional methodologies. In this case, topographic features can be obtained for the wider areas of our country, meeting the demand of most of the studies and activities related to topographic representation.

There is a variety of terminology to describe digital models that represent the earth's surface, its topography or other variables whose representation in space requires a continuous form of representation (such as temperature, pollution, etc.). In this case, it is important to differentiate between the terms to be adopted in this work. In a simplified manner, it is assumed that the DSM represent the terrain surface plus any existing objects on it, having a bearing on the reflectance value of the pixel. That is, if there are trees and buildings, the area represented refers their top. DTM, on the other hand, represent the real surface of the terrain.

The theme of this research is part of a larger project, developed at Remote Sensing and Environmental Studies Laboratory, ESPAÇO, in Department of Geography, UFRJ, with the support of CENPES / Petrobras, which studies on the use of various sensors, aerial and orbital, in the generation of threedimensional representations. 
Study area is represented by the influence area of OSBAT, São Sebastião-Cubatão Pipeline, located in São Paulo state. In this context, one of the sensors examined was LIDAR (Light Detection And Ranging), which constitutes an optical technology for remote sensing by aerial survey, which measures properties of reflected light in order to get the distance and / or other information regarding a given object. The laser profiling has emerged as a differentiated technology to obtain a high resolution DEM, allowing the extraction of DTM, as well as radar interferometry.

Thus, this study aims to evaluate the planialtimetric accuracy DSM and DTM generated from an aerial survey with LIDAR, using as reference the planimetric orthophotos obtained in aerial survey.

\section{METODOLOGY}

\subsection{Study Area}

Study area is located near the border between São Sebastião and Caraguatatuba, both municipalities of the northern coastline of the state of São Paulo. This area is inserted in the Serra do Mar (Sea Mountain Range), which presents height differences of up to $800 \mathrm{~m}$. The coverage area is predominantly of the dense forest habitat, vegetation characteristic of the Atlantic Forest biome. In the coast there are urban occupations ranging in density.

Figure 1 shows the general location of the study area.

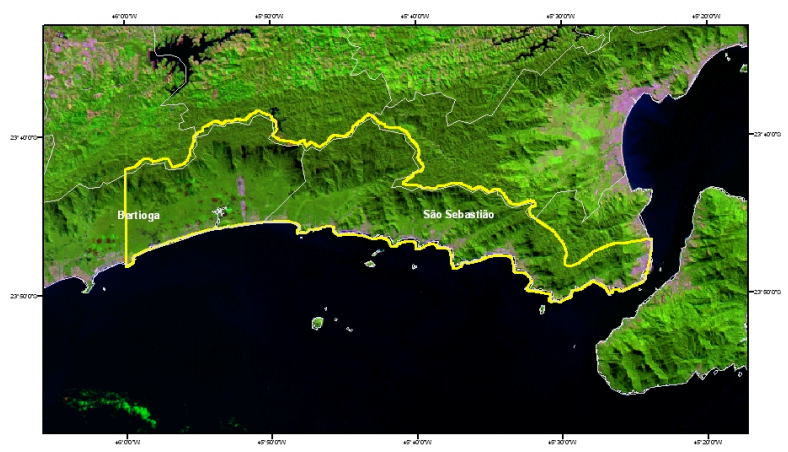

Figure 1: Location of Sudy Area

\subsection{Sensor's Description}

In the present project was adopted the sensor Optech ALTM 2050 (Airborne Laser Terrain Mapper). The survey aimed to meet the planimetric accuracies of $0.5 \mathrm{~m}$ and altimetric of 0.15 $\mathrm{m}$, with a density of points equivalent to one point every $80 \mathrm{~cm}$, in compliance with the PEC, class A, for the 1:2,000 scale. The estimated accuracy of DSM was $0.3 \mathrm{~m}$.

The company hired by CENPES (LACTEC) was responsible for the generation of the following products: point clouds in raw form $(\mathrm{x}, \mathrm{y}, \mathrm{z})$ using orthometric heights; point clouds (first and last pulse) per flight track, to check systematic errors; DTM in Geotiff, uniformly spaced, filtering small natural obstacles, like buildings and vegetation; DEM in Geotiff, also uniformly spaced; and an digital mosaic of georeferenced images.

\subsection{Fieldwork}

All points have been established in the field, with the use of GNSS of one frequency (L1) through static relative positioning, acquiring a minimum of 1,500 epochs, for a distance less than
$20 \mathrm{~km}$ to the base. This process consists in tracking data transmitted via satellite with receiving equipment located on a geodetic point (master) and another similar equipment located in the points to be determined. The stored data is processed further with specific software (postprocessing).

We sought the best possible distribution in the area of identifiable points in the images, trying to represent areas with different heights and slopes.

Initially, it was created a Network Support Geodesic Vertices determined from the GNSS network of IBGE Foundation, more specifically, from the vertex SAT 91606 located in Praia Grande. The determination of the coordinates of points of interest was carried out from that network.

\subsection{Analysis of the Planimetry}

LIDAR orthophotos used in the assessment are composed by 52 images, whose final mosaic with the distribution of ground check points is shown in Figure 2.

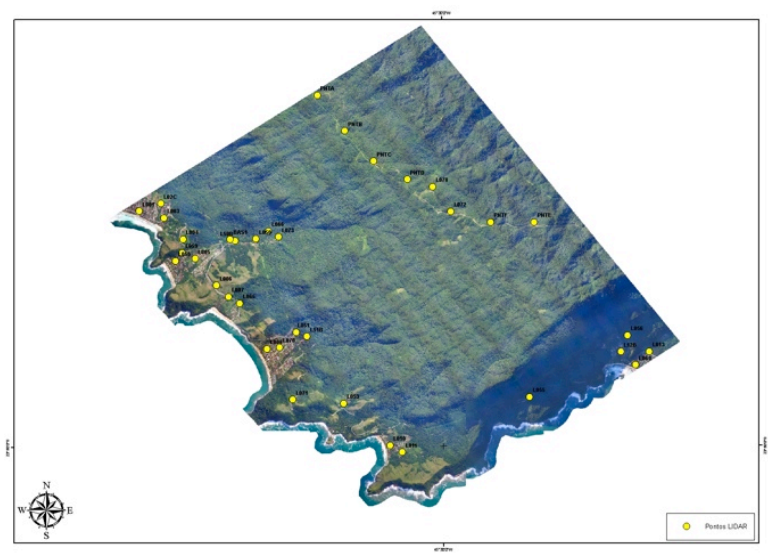

Figure 2: Distribution of ground check points on the mosaic of orthophotos

To evaluate the planimetric accuracy, 29 points were used and identified. The coordinates of these points were compared to their homologous in orthoimages and then the differences were calculated, obtaining the displacement of each point.

For the final evaluation of the results were considered the limits set by the PEC (Cartographic Accuracy Standards). PEC makes reference to the assessment of final products through the use of ground control points for checking how much the points located on a map deviate from their homologous located on the terrain. For each quality class - which can also be understood as accuracy - a standard value is specified to be reached by at least $90 \%$ of the points, as well as a limit value for the Mean Square Error - understood as synonymous of standard deviation (SD). Said simply, this norm applies both for planimetric as altimetric assessments.

According to the limits set by the PEC to assess the planimetric accuracy for 1:2,000 scale, we presented in Table 1 the established tolerances.

\begin{tabular}{|c|c|c|c|c|}
\cline { 4 - 5 } \multicolumn{2}{c}{} & \multicolumn{2}{c|}{$\mathbf{1 : 2 . 0 0 0}$} \\
\hline Class A & 0,5 & 0,3 & 1 & 0,6 \\
\hline
\end{tabular}




\begin{tabular}{|c|c|c|c|c|}
\hline Class B & 0,8 & 0,5 & 1,6 & 1 \\
\hline Class C & 1,0 & 0,6 & 2 & 1,2 \\
\hline
\end{tabular}

Table 1: PEC planimetric thresholds for 1:2,000 scale.

\subsection{Analysis of the Altimetry}

The altimetric accuracy assessment was performed on the DSM and DTM generated. For this analysis we used 36 ground control points, representing different relief conditions, including the higher parts of the area. Some of these points were only used in this assessment, since they were not well identified in the orthophotos.

According to the limits set by the PEC to assess the altimetric accuracy for 1:2,000 scale, we presented in Table 2 the established tolerances.

\begin{tabular}{|c|c|c|c|c|}
\multicolumn{2}{c}{} & \multicolumn{2}{c|}{$\begin{array}{c}1: 2.000 \\
\text { Contour Interval 1m }\end{array}$} \\
\hline & Tol. & SD & $\begin{array}{c}\text { Tol. } \\
(\mathbf{m})\end{array}$ & $\begin{array}{c}\text { SD } \\
(\mathbf{m})\end{array}$ \\
\hline Class A & $1 / 2$ & $1 / 3$ & 0.5 & 0.3 \\
\hline Class B & $3 / 5$ & $2 / 5$ & 0.6 & 0.4 \\
\hline Class C & $3 / 4$ & $1 / 2$ & 0.75 & 0.5 \\
\hline
\end{tabular}

Table 2: PEC altimetric thresholds for 1:2,000 scale.

The extraction of altimetric values from the DSM and DTM was made directly by the function Extract Values to Points in ArcGIS 9.3. We calculated the difference between the heights obtained from DSM and DTM to the value determined in the fieldwork. The differences in positive or negative values were compared with the tolerances established for the 1:2,000 scale. The final assessment of results, in the same way as for planimetry, used the defined percentage for PEC as reference.

\section{RESULTS}

\subsection{Planimetry}

The planimetric accuracy assessment performed on the orthophotos concluded that $93.10 \%$ of the points presented error less than $1 \mathrm{~m}$ (equivalent to 27 points of total 29) and standard deviation of $0.3 \mathrm{~m}$, validating its use in Class A for 1: 2000 scale.

\subsection{Altimetry}

Analyzing the accuracy of the DSM, it was concluded that only $77.8 \%$ of points meeting the class $A$ for $1: 2,000$ scale $(0.5 \mathrm{~m})$, according to PEC. Even considering the classes B and C, only $80.6 \%$ of points meeting the limits $(0.6$ and $0.75 \mathrm{~m})$. The calculated standard deviation $(0.73 \mathrm{~m})$ is also above the limits set by the SGP, including the class C for 1:2,000 scale $(0.5 \mathrm{~m})$.

Thus, the DSM becomes suitable for the 1:5,000 scale, class C, $91.66 \%$ of the points accepted (Table 3 ).

\begin{tabular}{|c|c|c|c|c|}
\cline { 3 - 5 } \multicolumn{2}{c}{} & \multicolumn{2}{c|}{$\begin{array}{c}1: 2.000 \\
\text { Contour Interval 1m }\end{array}$} \\
\hline Class A & Tol. & SD & $\begin{array}{c}\text { Tol. } \\
(\mathbf{m})\end{array}$ & $\begin{array}{c}\text { SD } \\
(\mathbf{m})\end{array}$ \\
\hline Class B & $3 / 2$ & $1 / 3$ & 1.0 & 0.7 \\
\hline Class C & $3 / 4$ & $1 / 2$ & 1.2 & 0.8 \\
\hline
\end{tabular}

Table 3: PEC altimetric thresholds for 1:5,000 scale.
The altitude of the area does not seem to be a problem for the LIDAR seen that the largest errors occurred in areas of low and medium altitudes. The points located in the highest areas were errors in the average.

There was a slight tendency in results, with average of errors of $0.27 \mathrm{~m}$ and sum of errors the $9.68 \mathrm{~m}$. There is therefore a small shift positive, indicating that the altitude values of MDS has slightly larger than observed in field. The major differences between 1.0 and $2.6 \mathrm{~m}$, observed in 7 points - appear to occur in lower areas.

In the DTM's assessment, considering the tolerance of $0.50 \mathrm{~m}$ for 1:2,000 scale (class A), it was found that not reached formally this class, as only $88.88 \%$ of the points (32 of total 36 ) have values below this limit. The calculated standard deviation $(0.4 \mathrm{~m})$ was also higher that established for Class A of these scale (threshold $0.3 \mathrm{~m}$ ). It is important to consider, however, that the values obtained are close to the threshold of $90 \%$; so it is interesting to investigate surveys in other areas. Anyway, considering the tolerance to $0.6 \mathrm{~m}$ (class B), $91.6 \%$ of the points lie within this threshold, perfectly meeting the specified for class B for 1:2,000 scale.

There were no indications of the trend results. The mean residue was $0.01 \mathrm{~m}$.

The continuation of this research is to evaluate the difference between the two models generated (DSM and DTM) and accuracy in defining the height of trees in support of studies requiring the quantification of biomass, or a greater characterization of the vegetation.

\section{CONCLUSIONS}

The analyses on the products from the LIDAR indicated their adoption to the scales 1:2,000 (class A for orthophotos and class B for DTM) and 1:5,000 (class C for DSM). It is important to emphasize that the raised area has characteristics of a very steep topography, it is important that new areas with different characteristics should be assessed in order to get an indication of wider use.

These results did not meet the specifications for the altimetry. One factor considered surprising was the result of DSM has been lower than the DTM. As the assessment points were determined in areas with no vegetation cover and the point cloud of the original DSM is denser than the DTM, it was expected that the first one had at least a similar behaviour to the second. The results of planimetry were also considered surprising, for different reasons, considering that it was not used a metric camera.

However, it should be emphasized that despite the accuracy of altimetry not having achieved the expected values, the results were considered very good. The height differences had always less than 2 meters when compared to values determined in the field. The exception occurred in only 1 point in the evaluation of DSM, which presented a positive difference of $2.58 \mathrm{~m}$.

Also regarding the altimetric assessment, are being made analysis using ground check points below the forest canopy in order to be able to assess the real accuracy of DTM in areas with forest cover.

It is true that an increasing number and variety of remote sensing products, from aerial or orbital surveys, has been offering the user a range of solutions for different applications, considering different precisions and details. The problem is that the speed that such products have been available for purchase 
far exceeds our ability to test them. Thus, it is imperative that such analyses are performed with more constancy, and more than that, structured so that consultations can be made in favour of a consistent decision with the needs of each study.

\section{ACKNOWLEDGEMENTS}

Our thanks to the Research Center Leopoldo Americo Miguez de Mello (CENPES), Petrobras, which supported this research by providing the resources necessary for its preparation.

\section{REFERENCES}

\section{References from Journals:}

TOUTIN, T. \& CHENG, P. (2002) Comparision of Automated Digital Elevation Model Extraction Results Using Along-Track ASTER and Across-Track SPOT Stereo Images. SPIE Journal, Optical Engeneering, 41 (9), p. 2102-2106.

TOUTIN, T. (2004) Comparison of Stereo-Extracted DTM from Different High-Resolution Sensors: SPOT-5, EROS-A, IKONOS-II, and QuickBird. IEEE Transactions on Geoscience and Remote Sensing. 42(10):2121-2129.

\section{References from Other Literature:}

BARROS, R. S. (2006) Avaliação da Altimetria de Modelos Digitais de Elevação Obtidos a Partir de Sensores Orbitais. [Rio de Janeiro], 2006 XIX, 172p.(IGEO/ UFRJ), D.Sc., Geografia, Tese - Universidade Federal do Rio de Janeiro, IGEO.

FERNANDES, M. C. (2004) Desenvolvimento de Rotina de Obtenção de Observações em Superfície Real: uma aplicação em Análises Geoecológicas. Tese de Doutorado. IGEO / UFRJ.

GOMES, R. A. T. (2002) Modelagem de previsão de movimentos de massa a partir da combinação de modelos de escorregamentos e corridas de massa. [Rio de Janeiro], 102p.(IGEO/ UFRJ), D.Sc., Geografia, Tese - Universidade Federal do Rio de Janeiro, IGEO.

GONÇAlVES, G. A.; da SILVA, C. R.; MITISHITA, E. A. (2005) Comparação dos Dados do SRTM com as RNs da Rede Geodésica Altimétrica do IBGE para Região Sul do Brasil. In: IV Colóquio Brasileiro de Ciências Geodésicas. Curitiba - PR. 